\title{
Efavirenz Based First Line Anti-Retroviral Drugs Disrupts Follicular Development-Evidence From Animal And Human Studies
}

Aigbe Ohihoin ( $\square$ aigbe.ohihoin@yahoo.com )

Esther Ngozi Ohihoin

Bolanle Olubusola Iranloye

Oladeji Olarenwaju

Arinze Okafor

Kalu Oji

Olufunto Kalejaiye

Airat Bakare

Ifeoma Ujomu

Olugbemiga Aina

Shola Ajibaye

Ada Okechukwu

Adekemi Kiladejo-Aderoba

Frank Medobi

Oliver Ezechi

Simon Taylor-Robinson

\section{Research}

Keywords: HIV, mother-to-child transmission, anti-retroviral agents, Tenofovir, Efavirenz, Lamivudine, reproductive function

Posted Date: May 7th, 2020

DOI: https://doi.org/10.21203/rs.3.rs-25915/v1

License: (c) (1) This work is licensed under a Creative Commons Attribution 4.0 International License. Read Full License 


\section{Abstract}

INTRODUCTION: Interventions to eliminate mother to child transmission of HIV has led to very low vertical transmission rate, however there are genuine concerns on long term effect of anti-retroviral drugs on future reproductive functions of females. There is currently paucity of information regarding the effect of anti-retroviral agents such as Tenofovir, Efavirenz and Lamivudine on the ovarian reserve of patients receiving anti-retroviral drugs.

METHODOLOGY: 1. ANIMAL STUDY: A total of 25 female Wistar rats, weighing between $150 \mathrm{~g}$ to $170 \mathrm{~g}$ were obtained and kept in the experimental animal house of the Nigerian Institute of Medical Research (NIMR) in Lagos, Nigeria. They were kept in clean cages at a temperature of 28 o C HUMAN STUDY: Women within the reproductive age range of 15-45 years were grouped into $A, B$ and $C$ categories. Group A was made up of HIV positive patients already on efavirenz based anti-retroviral therapy. Group B were HIV positive patients who were naïve to antiretroviral drugs at the time of recruitment. Group $\mathrm{C}$ participants were HIV negative women within the reproductive age range not being managed for Infertility.

RESULTS: ANIMAL STUDY : The mean count of antral follicles was significantly lower in the group that received efavirenz $(p=0.00)$. The corpus luteal count was significantly higher in the control group than study groups ( $p=0.033$ ) HUMAN STUDY: Average value of FSH is significantly higher in the HIV positive group who had antiretroviral medications when compared to HIV negative group. ( $P=0.039)$.Antral follicular count was significantly reduced in the group that received anti retrovirals (ARV). $P=0.009$

CONCLUSION: Evidence from this animal and human study, tend to suggest that efavirenz based antiretroviral medication disrupts follicular development.

\section{Introduction:}

Highly Active Anti-retroviral medications are anti-retroviral drugs that consist of at least three different anti-retroviral drugs with at least two of them having a different mechanism of action. There is evidence to suggest that the life expectancy of patients who are well managed for HIV infection are not so different from their HIV negative counterparts (Johnson, 2013; Nakagawa, 2013). Interventions to eliminate mother to child transmission of HIV has led to very low vertical transmission rate (Eunice, 2012).

There are however challenges with long-term usage of the anti-retroviral drugs as side effects of these drugs have become issues of concern. For instance Nucleoside reverse transcriptase inhibitors have been implicated in mithochondrial damage and haematological toxicity leading to anaemia (Dalakas, 1990; Arnaudo, 1991; Brinkman, 2000; Taedor, 2004)..

Adverse effects related to the central nervous system have been implicated in nonnucleoside reverse transcriptase inhibitors (Marzolini, 2001; Jeromea, 2001).There is some evidence to suggest that some of the side effects can affect the reproductive efficiency of the patients as evidence abound that some anti- 
retroviral drugs can affect sperm motility in some males (Van Leewen, 2008). There is also suggestion that antiretroviral drugs can lead to testicular atrophy (Mhawech, 2001). This evidence has not been clearly established especially for the female gametes.

Now that HIV positive individuals can live relatively normal lives, when managed with highly active antiretroviral drugs, there is therefore the desire for most of these patients to consider raising children and the integrity of their reproductive potential becomes an issue of concern.

There is currently paucity of information regarding the effect of anti-retroviral agents such as Tenofovir, Efavirenz and Lamivudine on the ovarian reserve of patients receiving anti-retroviral drugs. There are however no studies in animal models or humans in our environment to evaluate the effect of antiretroviral drugs on the reproductive functions of female patients receiving highly active anti-retroviral drugs.

This therefore is the rational for the conduct of this study

\section{OBJECTIVE OF THE STUDY:}

1. To ascertain the effect of Lamivudine, Tenofovir and Efavirenz on the follicular development of wistar rats

2. To determine the antral follicular count of HIV negative women within the reproductive age range.

3. To determine the antral follicular count of HIV positive women on Lamivudine, Tenofovir and Efavirenz who are within the reproductive age range

\section{Methods:}

\section{ANIMAL GROUP}

A total of 25 female wistar rats weighing about $150 \mathrm{~g}$ to $170 \mathrm{~g}$ were obtained and kept in the experimental animal house of the Nigerian Institute of Medical Research (NIMR). They were kept in a clean cage at a temperature of about $28 \mathrm{oC}$. The animals were kept in accordance to conditions stipulated by the U.S National Institute of Health $(\mathrm{NIH})$ involving a cycle of 12 hours light and dark. This is the stipulated standard required for the care of laboratory animals.

The source of feed was the normal laboratory chow obtained from Livestock Feeds,

Ikeja, and Lagos Nigeria). Water ad libitum will be added to the feeds

The laboratory animals were allowed two weeks to acclimatize to their new environment; thereafter the animals were apportioned in a random manner with five animals in each group in the following manner:

Group 1: (Control) This group was given water 
Group 2: This group received Efavirenz. The dosage was $9 \mathrm{mg} / \mathrm{kg}$ body weight through a vehicle of water

Group 3: This group was given Tenofovir. The administered dosage was $4.5 \mathrm{mg} / \mathrm{kg}$ body weight through a vehicle of water

Group 4: This group was given Lamivudine at a dosage of $4 \mathrm{mg} / \mathrm{kg}$ body weight through a vehicle of water

Group 5: This group received a combination of Efavirenz, Tenofovir and Lamivudine as a Fixed dose Combination. The dose combination Tenofovir $4.5 \mathrm{mg} / \mathrm{kg}$ body weight, Efavirenz $9 \mathrm{mg} / \mathrm{kg}$ body weight and Lamivudine $4 \mathrm{mg} / \mathrm{kg}$ body weight in a fixed dose combination through a vehicle of water

The experimental animals received daily treatment through a cannula for a period of four weeks.

The experimental animals received antiretroviral drugs efavirenz, tenofovir and Lamivudine at measured doses for weight, for a period of four weeks.

\section{LAMIVUDINE (3TC)}

Brand used: Mylan $150 \mathrm{mg}$ film coated oral tablet.

Predicted solubility of Lamivudine is $2.76 \mathrm{mg} / \mathrm{ml}$ which is approx $3 \mathrm{mg}$

(www.drudbank.ca/drugs/DB00709)

Therefore,

1 tablet was dissolved in $100 \mathrm{ml}$ of distilled water to form a $0.3 \mathrm{mg} / \mathrm{ml}$ solution

The tablet was crushed in a porcelain mortar and rinsed into a conical flask A $2 \mathrm{ml}$ oral syringe was used to administer the appropriate dose to the rat.

Administered dose $=4 \mathrm{mg} / \mathrm{kg}(0.2 \mathrm{mg} / 50 \mathrm{~g}$ body weight $)$

Thus $0.75 \mathrm{ml}$ of $0.3 \mathrm{mg} / \mathrm{ml}$ solution was administered to a rat weighing approx $150 \mathrm{~g}$

\section{EFAVIRENZ}

Brand used: Strides $200 \mathrm{mg}$ film coated oral tablets

Efavirenz has very low aqueous solubility $(9.19 \mathrm{micogram} / \mathrm{ml})^{\wedge}$

Half tablet dissolved in $100 \mathrm{ml}$ of distilled water to form a $1 \mathrm{mg} / \mathrm{ml}$ solution,

The $200 \mathrm{mg}$ tablet which is scored, was split with a tablet cutter

The half tablet was crushed in a porcelain mortar and rinsed into a conical flask 
Administered dose $=9.0 \mathrm{mg} / \mathrm{kg}(0.45 \mathrm{mg} / 50 \mathrm{~g}$ body weight $)$

Thus $2.5 \mathrm{ml}$ of $0.18 \mathrm{mg} / \mathrm{ml}$ solution was given to a rat weighing approx $150 \mathrm{~g}$

NB The solution was shaken very well before withdrawal with syringe to ensure uniformity of dose. (Smita, 2013)

\section{TENOFOVIR}

Brand used: Mylan $300 \mathrm{mg}$ film coated oral tablet

Solubility is $13.4 \mathrm{mg} / \mathrm{ml}$ (https://www.aidsreagent.org/reagentdetail)

A quarter $(1 / 4)$ tablet $(75 \mathrm{mg})$ dissolved in $100 \mathrm{ml}$ of distilled water to obtain $0.75 \mathrm{mg} / \mathrm{ml}$ solution

The $300 \mathrm{mg}$ tablet which is scored was split with a tablet cutter; the resulting half tablet was again split to form a quarter tablet

The quarter tablet was crushed in a porcelain mortar and rinsed into a conical flask

Administered dose $=4.5 \mathrm{mg} / \mathrm{kg}(0.22 \mathrm{mg} / 50 \mathrm{~g})$

$1.1 \mathrm{ml}$ of $0.04 \mathrm{mg} / \mathrm{ml}$ solution was given to a $150 \mathrm{~g}$ rat

\subsubsection{PROCEDURE FOR SACRIFICING:}

The rats were sacrificed during the oestrous phase of the cycle. The rats were inactivated by cervical dislocation. The skin and the subcutaneous tissue including the peritoneum were exposed to the abdomen. Blood samples were obtained from the heart. Some of the organs obtained include the ovaries, the oviducts and the uterus. These organs were preserved in saline solution initially and subsequently transferred to formalin solution.

\subsubsection{HISTOLOGY AND FOLLICULAR COUNT:}

The ovarian tissue obtained was be fixed in $10 \%$ formalin and thereafter dehydrated in a stepwise manner by the use of ethanol. After this process, it was cleared in Xylene and then embedded in a wax of paraffin. A section of the ovarian tissue embedded in paraffin was stained with Eosin and Haematoxolin. It was subsequently examined with the aid of a light microscope. To study folliculogenesis all tissue blocks were serially sliced. Follicle identification was based on the detection of a nucleus. The numbers of follicles were counted. Follicle recognition criterion on the slides was based on the type of epithelial cells surrounding them. For example, primordial follicles have squamulose cells whereas primary follicles are surrounded by cuboidal cells. This process was followed by examination under the light microscope at a magnification of 200 .

Micrographs were taken (Bancroft and Stevens, 2002). 


\section{INCLUSION CRITERIA FOR GROUP A:}

1. HIV positive females within the reproductive age range of $15-45$ years

2. HIV positive females within the reproductive age range of $15-45 y e a r s$ who are on highly active antiretroviral therapy combination of lamivudine, tenofovir and efavirenz

3. Women who satisfy criteria one and two above and have been on the medicationfor at least six months

4. Women who satisfy the criteria and are sexually active

\section{EXCLUSION CRITERIA:}

1. HIV positive women who are outside the reproductive age range

2. HIV positive women who have not commenced HAART

3. HIV positive women who are pregnant

4. Women within the reproductive age range who are being evaluated for infertility

\section{INCLUSION CRITERIA FOR GROUP B:}

1. HIV positive women within the reproductive age range

2. HIV positive women with a new diagnosis of HIV and have not been commenced on Anti-retroviral drugs

3. Satisfy criteria above and sexually active

\section{EXCLUSION CRITERIA:}

1. HIV positive women who are outside the reproductive age range

2. HIV positive women who have been commenced on Anti-retroviral medications

3. HIV positive women who are pregnant

4. Women within the reproductive age range who are being evaluated for infertility

\section{INCLUSION CRITERIA FOR GROUP C:}

1. HIV Negative women within the reproductive age range (15-45 years)

2. HIV Negative women who satisfy the criteria 1 above and are sexually active

3. HIV Negative women who satisfy the criteria 1 and 2 above and not being evaluated for Infertility

\section{EXCLUSION CRITERIA FOR GROUP C:}

1. HIV negative Women within the reproductive age range who are not sexually active

2. HIV negative women within the reproductive age range who are being evaluated for Infertility 


\subsubsection{SAMPLE SIZE CALCULATION:}

The sample size was determined using the following formula:

$N=Z^{2} P q$

$D^{2}$

$\mathrm{N}=$ Sample size

$Z=Z$ value at $95 \%$ (0.95) confidence limit read from standardized normal distribution table

$\mathrm{P}=$ Estimated prevalence on the basis of previous studies

$Q=1-P$

$\mathrm{D}=$ Precision

For this study

$P=($ Prevalence of HIV in Lagos $)=1.4 \%$

$D=50 \%(0.05)$

$Q=0.98$

$\mathrm{N}=\underline{1.96}^{2} \times \underline{0.02 \times 0.99}$

$(0.05)^{2}$

$=16$

A total of 48 participants will be recruited into the study.

HUMAN STUDY GROUP A: 16 participants who are HIV positive patients and have been on anti-retroviral drugs Lamivudine, Efavirenz, and Tenofovir for up to six months and not being evaluated for Infertility

HUMAN STUDY GROUP B: 16 participants who were new diagnosis of HIV but treatment naïve and being evaluated towards commencement of HAART

HUMAN STUDY GROUP C: The other 16 participants will be HIV negative females who are within the reproductive age range and not being evaluated for Infertility

\section{ULTRASOUND PROCEDURE FOR ANTRAL FOLLICULAR COUNT:}

Antral follicular count is performed for female humans during the follicular phase of the menstrual cycle prior to ovulation. The procedure is performed more specifically during the early follicular phase after the 
menstrual period.

The preferred method for the determination of the antral follicular count is via a vaginal ultrasound scan at a frequency of 6-8 mega hertz. The Mindray M7 ultrasound machine was used for this procedure. The frequency of the vaginal transducer to be used is 7 megahertz.

The patients were adequately counselled for the procedure and an additional verbal consent obtained after the signed informed consent used to recruit patients for the study. A female chaperone was present all through the procedure. The transducer was covered with a protective sheath before a gel was applied to it. This was done to eliminate the risk of infection. The aim of the gel is to improve the transmission of the ultrasound beam, by eliminating vaccum. The transducer was introduced in an anterior-posterior direction. Gentle adjustment of the transducer by sweeping to the right and left to visualize was done and thereafter the antral follicles counted on both ovaries

\subsubsection{ETHICAL CONSIDERATION}

Ethical approval was obtained for the conduct of the study from the Institutional Review Board (IRB) of the Nigerian Institute of Medical Research (NIMR).

\section{INFORMED CONSENT:}

A written informed consent was obtained from the patients.

\section{Results:}

ANIMAL STUDY: COMPARISON OF FOLLICULAR COUNT,AMH, OESTRADIOL,LH AND FSH BETWEEN THE STUDY GROUPS AND THE CONTROL: 


\begin{tabular}{|c|c|c|c|c|c|c|c|c|}
\hline 3LE & $\begin{array}{l}\text { CONTRO } \\
\mathrm{L}\end{array}$ & EFV & $\mathrm{TDF}$ & 3TC & FDC & $\begin{array}{l}\text { STATISTIC } \\
\text { AL TEST }\end{array}$ & $\begin{array}{l}\text { CONFIDENC } \\
\text { E INTERVAL }\end{array}$ & $\begin{array}{l}\mathrm{P} \\
\text { VALU } \\
\mathrm{E}\end{array}$ \\
\hline RY & 4.60 & 1.60 & 0.60 & 3.00 & 1.60 & ANOVA & $1.30-3.26$ & 0.055 \\
\hline $\mathrm{L}$ & 2.60 & 0.00 & 0.20 & 0.40 & 0.00 & ANOVA & $0.12-1.16$ & 0.000 \\
\hline DAR & 2.60 & 1.00 & 0.60 & 1.40 & 2.20 & ANOVA & $1.00-2.12$ & 0.098 \\
\hline [AN & 0.08 & 0.06 & 0.25 & 0.00 & 0.40 & ANOVA & $0.14-0.69$ & 0.374 \\
\hline \multirow{2}{*}{$\begin{array}{l}\mathrm{S} \\
\mathrm{M}\end{array}$} & 8.00 & 4.40 & 4.00 & 4.80 & 5.40 & ANOVA & $4.37-6.27$ & 0.033 \\
\hline & 11.2000 & $\begin{array}{l}6.750 \\
0\end{array}$ & 7.3200 & 8.2700 & 6.6000 & ANOVA & $\begin{array}{l}6.6275- \\
9.4285\end{array}$ & 0.180 \\
\hline \multirow[t]{3}{*}{ ADI } & 10.3500 & $\begin{array}{l}9.400 \\
0\end{array}$ & $\begin{array}{l}27.104 \\
0\end{array}$ & 15.2000 & $\begin{array}{l}17.600 \\
0\end{array}$ & ANOVA & $\begin{array}{l}9.6829- \\
22.1787\end{array}$ & 0.373 \\
\hline & 0.0420 & $\begin{array}{l}0.028 \\
0\end{array}$ & 0.0320 & 0.0300 & 0.0320 & ANOVA & $\begin{array}{l}0.288- \\
0.0368\end{array}$ & 0.190 \\
\hline & 0.9200 & $\begin{array}{l}1.168 \\
0\end{array}$ & 0.2380 & 3.1600 & 3.4400 & ANOVA & $\begin{array}{l}0.6817- \\
2.8887\end{array}$ & 0.224 \\
\hline
\end{tabular}

HUMAN STUDY: The average age of the HIV negative patients was 32 years, while that of the HIV positive patients without drug was 33.40 years and that of the HIV positive patients with drug was 37.58 . Across the study groups, none of the participants had been involved in smoking or significant consumption of alcohol. The average CD4 count was 725.27 and the average viral load was 20 . The average duration of use of anti-retroviral medication was 39 months 


\begin{tabular}{|c|c|c|c|c|c|c|}
\hline GROUP & $\mathrm{N}$ & Mean & $\begin{array}{l}\text { Std } \\
\text { Deviation }\end{array}$ & $\begin{array}{l}\text { STATISTICAL } \\
\text { TEST }\end{array}$ & $\begin{array}{l}\text { CONFIDENCE } \\
\text { INTERVAL }\end{array}$ & $\begin{array}{l}\mathrm{P} \\
\text { VALUE }\end{array}$ \\
\hline $\begin{array}{l}\text { HIV } \\
\text { Negative }\end{array}$ & 16 & 4.4360 & 2.22752 & T-TEST & $\begin{array}{l}-28.36010- \\
8.12810\end{array}$ & 0.039 \\
\hline $\begin{array}{l}\text { Reactive with } \\
\text { drugs }\end{array}$ & 16 & 14.5520 & 17.54999 & & $\begin{array}{l}-31.81431- \\
11.58231\end{array}$ & \\
\hline
\end{tabular}

Average value of FSH is significantly higher in the HIV positive group who had antiretroviral medications when compared to HIV negative group. $P=0.039$

COMPARING AVERAGE FSH VALUE IN HIV NEGATIVE VESRUS HIV POSITIVE, NOT ON DRUGS 


\begin{tabular}{|c|c|c|c|c|c|c|}
\hline GROUP & $\mathrm{N}$ & Mean & $\begin{array}{l}\text { Std } \\
\text { Deviation }\end{array}$ & $\begin{array}{l}\text { STATISTICAL } \\
\text { TEST }\end{array}$ & $\begin{array}{l}\text { CONFIDENCE } \\
\text { INTERVAL }\end{array}$ & $\begin{array}{l}\mathrm{P} \\
\text { VALUE }\end{array}$ \\
\hline $\begin{array}{l}\text { Reactive without } \\
\text { drugs }\end{array}$ & 16 & 6.6900 & 2.22752 & T-TEST & $-9.59155-5.08355$ & 0.122 \\
\hline HIV Negative & 16 & 4.4360 & 6.75734 & & $\begin{array}{l}-10.50524- \\
5.99724\end{array}$ & \\
\hline
\end{tabular}

There was no statistical significant difference in the mean FSH levels of HIV negative respondents and the HIV positive respondents not on drugs

COMPARING AVERAGE OESTRADIOL VALUE IN ALL THREE GROUPS 


\begin{tabular}{|c|c|c|c|c|c|c|}
\hline GROUP & $\mathrm{N}$ & Mean & $\begin{array}{l}\text { Std } \\
\text { Deviation }\end{array}$ & $\begin{array}{l}\text { STATISTICAL } \\
\text { TEST }\end{array}$ & $\begin{array}{l}\text { CONFIDENCE } \\
\text { INTERVAL }\end{array}$ & $\begin{array}{l}\mathrm{P} \\
\text { VALUE }\end{array}$ \\
\hline $\begin{array}{l}\text { HIV } \\
\text { Negative }\end{array}$ & 16 & 38.20 & 22.429 & ANOVA & $10.35-66.05$ & 0.580 \\
\hline $\begin{array}{l}\text { Reactive without } \\
\text { drugs }\end{array}$ & 16 & 52.54 & 29.270 & & $16.20-88.88$ & \\
\hline $\begin{array}{l}\text { Reactive with } \\
\text { drugs }\end{array}$ & 16 & 36.00 & 27.674 & & $1.64-70.36$ & \\
\hline
\end{tabular}

COMPARING AVERAGE LH VALUE IN HIV NEGATIVE VERSUS HIV POSITIVE ON DRUGS 


\begin{tabular}{|c|c|c|c|c|c|c|}
\hline GROUP & $\mathrm{N}$ & Mean & $\begin{array}{l}\text { Std } \\
\text { Deviation }\end{array}$ & $\begin{array}{l}\text { STATISTICAL } \\
\text { TEST }\end{array}$ & $\begin{array}{l}\text { CONFIDENCE } \\
\text { INTERVAL }\end{array}$ & $\begin{array}{l}\mathrm{P} \\
\text { VALUE }\end{array}$ \\
\hline $\begin{array}{l}\text { HIV } \\
\text { Negative }\end{array}$ & 16 & 5.91 & 1.092 & T-TEST & $-44.979-9.883$ & 0.014 \\
\hline $\begin{array}{l}\text { Reactive with } \\
\text { drugs }\end{array}$ & 16 & 23.46 & 26.577 & & $\begin{array}{l}-50.532- \\
15.436\end{array}$ & \\
\hline
\end{tabular}

LH was significantly higher in the HIV positive group on anti-retroviral medication than the HIV negative group. $(p=0.014)$

ANTRAL FOLLICULAR COUNT ACROSS THE THREE COHORTS

ANTRAL FOLLICULAR COUNT ACROSS THE THREE COHORTS
\begin{tabular}{|l|l|l|l|l|l|l|}
\hline GROUP & $\mathrm{N}$ & Mean & $\begin{array}{l}\text { Std } \\
\text { Deviation }\end{array}$ & $\begin{array}{l}\text { STATISTICAL } \\
\text { TEST }\end{array}$ & $\begin{array}{l}\text { CONFIDENCE } \\
\text { INTERVAL }\end{array}$ & $\begin{array}{l}\text { P } \\
\text { VALUE }\end{array}$ \\
\hline $\begin{array}{l}\text { Reactive } \\
\text { with drugs }\end{array}$ & 16 & 4.50 & 3.631 & ANOVA & $2.19-6.81$ & 0.009 \\
\hline $\begin{array}{l}\text { Reactive } \\
\text { without } \\
\text { drugs }\end{array}$ & 16 & 10.10 & 5.567 & & $6.12-14.08$ & \\
\hline $\begin{array}{l}\text { HIV } \\
\text { Negative }\end{array}$ & 16 & 10.57 & 5.612 & & $7.33-13.81$ & \\
\hline
\end{tabular}

Antral follicular count was significantly reduced in the group that received anti retrovirals (ARV). $P=0.009$ 


\section{Discussion}

\section{ANIMAL STUDY}

Folliculogenesis is a key component of reproductive functions in both lower animals and human subjects. Folliculogenesis is the process that leads to the formation of a preovulatory or dominant follicle that houses the oocyte. Folliculogenesis involves the primordial follicle maturing to become the primary follicle, the secondary or pre-antral follicle and then the tertiary or antral follicle.(White and Porterfield, 2012). The antral follicle eventually evolves to become the pre-ovulatory follicle . During folliculogenesis, a number of follicles are destroyed and end up as atretic follicle. (White and Porterfield , 2012)

The rat model is ideal for the study of folliculogenesis due to the relatively short cycle length averaging 4.8 days (Andrew and Ojeda, 1981). Follicular development is under the control of both hormornal and growth factors. (Fortune 2003).

Findings from this study revealed a reduction in the average number of follicles across various stages of follicular development in the study groups when compared to control. This reduction in the average number of follicles showed statistical significance $(P=0.00)$. The reduction in the number of follicles was more marked in the study group that received efavirenz when compared to the study group that received, tenofovir, lamivudine and a combination of all three drugs. The affectation was more with follicles at the antral stage of development. The reduction of follicles in the group that received efavirenz was not seen in the other study groups receiving other anti-retroviral medications-tenofovir and lamivudine. Efavirenz based combination is in common usage as first line anti-retroviral combination in HIV positive women within the reproductive age range.

A decrease in the number of follicles has been observed in human females as they age. Smoking is also associated with a decrease in the number of follicles. Decrease in follicles has also been observed in individuals who are receiving cytotoxic medications as well as those who are exposed to radiotherapy. (Peck, 2016).

A decrease follicular count was however documented in female wistar rats exposed to Heracleum persicum (H. persicum). (Hemati, 2012). This is a herbal medicinal plant famously used in Iran and Asiantic nations of the world for a variety of medicinal purposes. This plant has been used in some traditional settings as a form of contraception.

The average level of Anti-mullerian hormone in this study was lower in the study group that received antiretroviral therapy when compared with the control group. The average AMH in the cohort of rats that received the combined anti-retroviral therapy and efavirenz alone was lower than the control. The difference was however not statistically significant. $(p=0.180)$. AMH (Anti-mullerian hormone) is a marker for reproductive potential and ovarian function. Levels are very low in neonates and early childhood but begin to rise during puberty. As reproductive capacity declines with age due to depleting ovarian reserve, there is a decrease in anti-mullerian hormone. As the menopause is being approached, 
anti-mullerian hormone diminishes. AMH values thus correlates with the number of antral follicles in the ovary. This has been demonstrated in mice as the antral follicular count is directly proportional to the levels of AMH. (Kevenaar, 2006). AMH is used for the estimation of ovarian reserve and a prediction of the fertility potential in females. The correlation of $\mathrm{AMH}$ with antral follicular count is due to the fact that $\mathrm{AMH}$ is secreted by the granulosa cells of the developing follicle. Changes in the level of AMH are known to occur relatively early as it relates to ovarian aging. Changes in AMH IS known to predate changes in FSH levels and inhibin B.(Nathalie and Nathalie 2004). Anti-mullerian hormone is thus a better predictor of ovarian reserve than Inhibin B and FSH. It is also a more reliable marker of ovarian reserve because it does not fluctuate through the menstrual cycle.(Nathalie and Nathalie 2004). In humans, normal levels of $\mathrm{AMH}$ is $1.5-4.0 \mathrm{ng} / \mathrm{m} /$. This hormone is also relevant in-utero for inhibiting mullerian growth and the the evolution of the fetus to the male sex. (White and Poterfield ,2012). Recent studies tend to suggest that AMH could be protective against ovarian depletion induced by chemotherapy for the treatment of malignancies. (Motohiro, 2016).

Changes in the level of AMH have been shown to influence litter size in mice. Mclennan I.S. and coworkers demonstrated that mice with either elevated or diminished levels of anti-mullerian hormone have reduced litter size. (Mclennan, 2017).

Serum levels of oestradiol fluctuate throughout the oestrous cycle and as such oestradiol is not a reliable predictor of reproductive functions. (Nathalie and Nathalie, 2004). Oestradiol is produced by the granulosa and theca cells of the developing follicle. The production of oestradiol is under the control of gonoadotropins from the anterior pituitary. Oestradiol regulate female reproductive functions and it is diminished with ageing and depletion of follicles.(White and Poterfield, 2012)

In this study, there was a diminished average level of oestradiol in the study group when compared to the study groups. This elevation was however not statistically significant. Some workers have however noted elevated levels of oestradiol in males who are being treated with anti-retroviral drugs, this elevation lead to sexual dysfunction in these males. (Lamba, 2004). There is need to elucidate through research if this finding applies to HIV positive women on highly active anti-retroviral therapy.

Anti-retroviral drugs have been known to counteract the contraceptive benefits of oestrogen containing oral contraceptive pill and invariably leads to higher contraceptive failure rate. (Anderson, 2007)

\section{THE EFFECT OF ANTI-RETROVIRAL DRUGS ON THE SERUM LEVEL OF FSH AND LH}

FSH AND LH are both referred to as gonadotropins. These hormones are products of the anterior pituitary. $\mathrm{LH}$ and FSH play crucial roles in the development of the follicles and other reproductive functions They are trophic hormones and as such they are known to stimulate the gonads (White and Poterfield , 2012).

In this study, serum levels of LH did not show any significant difference between the study groups and the control group. The analysis of the levels of FSH and LH between the study groups and the control revealed significant degree of variation. FSH level in the group that received TDF was reduced when 
compared to the control group. FSH level was however markedly elevated in the group that received FDC when compared with the control group, this difference was statistically significant $(p=0.05)$. In other study groups that received efavirenz, FSH was marginally elevated when compared to the control group. FSH was however markedly elevated in the lamivudine group when compared against control, but this difference was not statistically significant $(p=0.08)$. FSH level is known to correlate with ovarian failure and serum level of oestrogen. This relationship is inverse as depletion of ovarian follicles, leads to reduced levels of oestrogen. The reduced levels of oestrogen obliterates the negative feedback of oestrogen on FSH. This leads to marked elevation of FSH. Elevation of FSH is used as a marker of ovarian function, although it is not as reliable and accurate as the use of $\mathrm{AMH}$ and antral follicular count.

Concerns have been raised about the age of menopause of women being managed for HIV. It is thought that women who are being managed for HIV will get to the menopause earlier than their HIV negative counterparts. (Fan,2008). There is however no clear evidence to suggest if this is due to the effect of the disease or the medications.FSH levels in these individuals have been used as a marker for ovarian function in these group of individuals, although challenges do exist with its usage, due to fluctuation through the menstrual cycle.(Kahwati,2005).

\section{HUMAN STUDY}

The study involved women within the reproductive age range. The average age of the HIV negative patients was 32 years, while that of the HIV positive patients without drug was 33.40 years and that of the HIV positive patients with drug was 37.58 This showed that the human research subjects were well matched for age, this minimizing the risk of bias. Moreover, individuals within this age category are still actively involved with reproductive processes.

Fertility and reproductive potential has been known to decline with advancing age. (Liu , 2012). The table also showed that most of the participants across the three study groups did not smoke nor consume alcohol. Smoking and alcohol consumption is a cofounder in this study as binge drinking has been shown to be associated with premature ovarian failure and depletion of ovarian reserve.(Hawkins, 2016)

Female smoking has been shown to be associated with depletion in ovarian reserve. (Firns, 2015).

Antral Follicular Count (AFC) is a marker for ovarian reserve and a reflection of the fertility potential of human females. It is the gold standard for the measurement of ovarian reserve of human females. $(A C O G, 2015)$. It can be used in isolation in the determination of patients who will require egg donation in preparation for Invitro fertilization using donor egg. (ACOG, 2015).

AFC measurement in this study was done with the aid of a four dimensional colour Doppler ultrasound machine with a transvaginal transducer. Colour Doppler ultrasound is superior to plain ultrasound machine because they can discriminate follicles from blood vessels. The study revealed that AFC was significantly lower in HIV positive individuals receiving anti-retroviral therapy when compared to the 
participants in the other cohorts $(p=0.009)$. Antral follicular count values have been shown to be a better predictor of hyperstimulation in IVF cycles when compared to AMH. (Christianson M.S., 2016).

This reduction in AFC noticed in the human population was also documented in the rat model used for this study. The reduction in AFC in the human population was also reflected in the findings obtained from estimation of the FSH level of the human research subjects used for the study as discussed below.

AFC estimation is done during the follicular phase of the menstrual cycle, usually between days 7-10 as this is the period of the cycle were follicular recruitment occurs. Values above 8 are considered normal. The normal range is between 8-16 antral follicles. Patients with Polysystic ovarian syndrome (PCOS) tend to have high AFC . AFC is usually over 18 . .

HIV has been shown by some studies to negatively impact the values of AFC.(Ohl .J, 2010). The impact of anti-retroviral medications on AFC is however not clear.

The average CD4 values across the study population who are HIV positive was 725 and the average viral load was 20 copies per $\mathrm{ml}$. This finding shows that human participants used for the study, were immunologically and virologically stable, hence the influence of the pathology of the disease condition cannot be used as a cofounder influencing the findings above. Patients with viral load of $20 \mathrm{copies} / \mathrm{ml}$ are classified as undetectable viraemia. These patients are therefore in a good state of health.

\section{HORMONE PROFILE ACROSS THE THREE GROUPS}

In these cohorts of human participants, used for the conduct of the study, serum levels of FSH, LH, and Oestradiol were evaluated during the follicular phase. Serum levels of these hormones are known to fluctuate during the menstrual cycle, hence values used in the evaluation of patients are best done during the follicular phase of the cycle, when follicular recruitment is taken place. (Fritz and Speroff, 2011). The mean FSH value for the research participants who are positive and on drug was higher than the other two cohorts. Average value of FSH is significantly higher in the HIV positive group who had anti-retroviral medications when compared to HIV negative group. $\mathrm{P}=0.039$. On the contrary, there was no statistical significant difference between the average FSH levels in HIV positive individuals not on drug and HIV negative individuals when compared.$(p=0.222)$. One can possibly infer from this finding that HIV positivity did not significantly lead to a higher than normal FSH values in these individuals when compared to their HIV negative counterparts. However HIV individuals who have been on long term usage of efavirenz based combination tend to have higher than normal FSH values when compared to individuals in the other two cohorts.

A Normal FSH value in reproductive aged women during the follicular phase is $3.77 .9 \mathrm{miu} / \mathrm{ml}$. (Sofronescu G.A., and Wheeler M.T.,2015). FSH value is a predictor of ovarian reserve and should directly correlate with values of antral follicular count. The average FSH value in patients who are HIV positive and on drug was higher than the range for normal. This is also true for patients who are HIV positive and not on drug, but the patients who are HIV positive and on drugs had a the worst FSH value. Values above 
30.6miu/ml are considered as menopausal. (Sofronescu G.A., and Wheeler M.T., 2015). It should be noted however that FSH value is a late predictor of ovarian reserve as $\mathrm{AMH}$ and antral follicular count are early and more accurate predictors of ovarian reserve. (Nathalie and Nathalie, 2004). Santoro and co-workers who studied the factors affecting reproductive hormones in HIV positive substance using women within the middle age range came up with the conclusion that use of anti-retroviral drugs in these cohort of patients was associated with higher FSH , LH and Oestradiol when compared with controls. (Santoro. N., 2007).

Estimation of serum levels of oestradiol for reproductive functions is usually done during the follicular phase of the cycle during recruitment of the follicles. Normal range for oestradiol in human females is 27123pg/ml.(Sofronescu A.G. and Staros B.E., 2015) . In this study, the average serum level of oestradiol was lower than the average serum level of oestradiol in the other two cohorts. The average serum level of oestradiol was $36.00 \mathrm{pg} / \mathrm{ml}$ for HIV positive on drugs while that of HIV positive not on drug was $52.50 \mathrm{pg} / \mathrm{m} /$. The average serum level of oestradiol for respondents who are HIV negative was $38.20 \mathrm{ng} / \mathrm{m} /$. This differences were however not statistically significant. A low level of oestradiol is present in premature ovarian failure and the menopause. Oestradiol levels tend to exhibit an inverse relationship with levels of Follicle stimulating hormone and a direct relationship with levels of AMH.(Fritz and

Speroff,2011). This pattern is not always the case as serum levels of both oestradiol and FSH are late and less than accurate predictors of ovarian reserve. (Nathalie and Nathalie, 2004). Oestradiol levels below $40 \mathrm{pg} / \mathrm{ml}$ are reflective of a value close to that in the menopausal range.

The normal range of LH during the follicular phase is $1-18 \mathrm{miu} / \mathrm{ml}$. (Charbek.E. and Wheeler M.T, 2015). $\mathrm{LH}$ is not a reliable predictor of ovarian reserve and reproductive potential because of its fluctuation over the cycle duration and also because of the broad range of value. LH is however useful when interpreted in conjunction with FSH when making a diagnosis of Polycystic ovarian syndrome. In this regard LH/FSH ratio becomes relevant. The normal value is $1: 1$ but in patients with PCOS, the ratio becomes 2:1 or 3:1 due to the elevated values of LH. (Fritz and Speroff, 2011).

In this study, average LH value was more elevated in the HIV positive group than the HIV negative group. The elevation was more marked in the HIV positive group on drug than the HIV positive group not on drug. This difference was statistically significant $(p=0.014)$. Elevated LH levels when used in conjuction with FSH levels suggest anovulation . (Santoro N., 2007)

\section{RELATING THE ANIMAL STUDY AND THE HUMAN STUDY}

The rat model is a good model for the study of reproductive functions in higher mammals because of the relatively short cycle length and it allows for in-depth study of parts of the reproductive system of higher animals through relative ease of obtaining tissue from the reproductive system for study. 
A significant reduction in the antral follicles of the wistar rats that received the medication was also observed $(p=0.00)$. This was also mirrored in the findings from the human study that revealed a reduction

in the mean level of antral follicular count in the HIV positive patients on medication $(p=0.009)$

Surrogate markers of ovarian reserve such as $\mathrm{AMH}$ and $\mathrm{FSH}$ values were consistently in favour of diminished ovarian reserve in the group of rats that had the anti-retroviral medication. This same effect was demonstrated in the human population as serum levels of FSH showed pattern consistent with relatively diminished ovarian reserve in patients receiving anti-retroviral therapy when compared to age matched controls who are HIV positive but not receiving anti-retroviral therapy

\section{Conclusions}

This study has shown that long term usage of efavirenz based anti-retroviral medications is associated with compromised follicular development and dysfunctional reproductive hormone profile.

The implication of this finding as it relates to use of efavirennz based anti-retroviral medications in the management of women in the reproductive age range is far reaching. There is therefore an urgent need to review the current regimen in use for the management of women within the reproductive age range who are being managed with efavirenz based combination

\section{References}

1. Arnaudo E, Dalakas M, Shanske S, Moraes C, DiMauro S, Schon E. Depletion of muscle mitochondrial DNA in AIDS patients with zidovudine-induced myopathy. Lancet. 1991;337:508-10.

2. Bancroft J, Stevens A. Theory and Practice of Histological Techniques. 4e. Notingham: Churchill Livingstone; 2002.

3. Brinkman K, Kakuda T. Mitochondrial toxicity of nucleoside analogue reverse transcriptase inhibitors: a looming obstacle for long-term antiretroviral therapy? Curr Opin Infect Dis. 2000;13:5-11.

4. Christianson MS, Shonham G, Tobler KJ, Zhao Y, et al. "Measurement of Antral Follicular Count in Patients Undergoing Invitro fertilization Treatment : Results of a world wide web survey ". J Assist Reprod Genet. 2015;32(10):1435-40.

5. Dalakas M, Illa I, Pezeshkpour G, Laukaitis J, Cohen B, Griffin J. Mitochondrial myopathy caused by long-term zidovudine therapy. N Engl J Med. 1990;322:1098-105.

6. Cruzat FirnsS, Keane FC, Joesbury NK, Andy KA.H.L. et al (2015) "The effect of cigarette Smoking, Alcohol Consumption and Fruit and Vegetable Consumption On IVF outcomes: A review and Presentation of Original Data Reproductive biology and endocrinology 13:134.

7. Fortune JE. The early stages of follicular development: activation of primordial follicles and growth of preantral follicles. Animal Reproduction Science. 2003;78:135-63.

8. Marsh E.E.

Hawkins BL, Bernadi LA, Dr Chavez PJ, Baird DD, Carnethon MR. Marsh E.E. (2016). 
9. "Alcohol. Cigarette Smoking and Ovarian Reserve in Reproductive Age African American Women" Am J Obstet Gynecol. Doi: 10. 1016/.

10. Azarnia HematiA, Nabiuni M, Mirabolghasemi M G., et al. "Effect of the Hydroalcoholic Extract of Heracleum persicum (Golpar) on Folliculogenesis in Female Wistar Rats. Cell J Spring. 2012;14(1):47-52.

11. Jérômea Buclin T. (2001). "Efavirenz plasma levels can predict treatment failure and central nervous system side effects in HIV 1 infected patients" AIDS: (2001)-vol 15- Iss 1-pp 71-75.

12. Johnson L, Mossong J, Dorrington R, Schomaker M, Hoffmann C, Keiser O, Fox M, Wood R, Prozesky H, Giddy J, Garone D, Cornell M, Egger M, Boulle A. Life expectancies of South African adults starting antiretroviral treatment: collaborative analysis of cohort studies. PLoS Med. 2013;10:e1001418.

13. Case LiuK .A., (2011) "Advanced Reproductive age and Fertility " Reproductive endocrinology and Infertility committee Volume 33, Issue 11, Pages 1165-1175.

14. Marzolini C, Telenti A, Decosterd L, Greub G, Biollaz L, Day B, Copeland W. Mitochondrial toxicity of non-reverse transcriptase inhibiting antiviral drugs: an integrated cellular perspective. Nat Rev Drug Discov. 2003;2:812-22.

15. Mhawech $\mathrm{P}$, Onorato $\mathrm{M}$, Uchida T, Borucki M. Testicular atrophy in 80 HIVpositive patients: a multivariate statistical analysis. Int J STD AIDS Apr. 2001;12(4):221-4.

16. Nakagawa F, May M, Phillips A. Life expectancy living with HIV: recent estimates and future implications. Curr Opin Infect Dis. 2013;26:17-25.

17. "Alterations in Ovarian

Partisani OhIJ, Demangeat M, Binder-Foucard C F, et al (2010) "Alterations in Ovarian.

18. Reserve Test in. Human Immunodeficciency Virus Infected women" Gynecol Obstet Fertil 38(5) 3137.

19. Peck DJ, Quaas MA, Craig BL, Soules RM, et al. Lifestyle factors associated with histologically derived human ovarian non growing follicle count in aged women. Hum Reprod. 2016;31(1):150-7.

20. Smita, Kolhe, Dr. Praveen Chaudhari, Dhananjay et al (2013) "Dissolution Enhancement of.

21. Poorly Water Soluble Efavirenz by Hot Melt Extrusion Technique”. Int. J. Drug Dev. \& Res., 5(2): 368381. doi: doi.

22. Taedor A, Taedor V, Luca V. (2004). Side effects of Anti-retroviral Therapy available on www.europepmc.org acessed 21/03/2017.

23. F.

Prins

Van-Leeuwen E, Wit F, Repping S, Eeftinck S, Jan K, Reiss P, van der Veen. F., Prins.

24. J. (2008). Effects of Antiretroviral therapy on semen quality. AIDS:22;5 pp 637-642. 